\title{
Effect of Shear Rate Shear Strength of Sand Mixed with Fibre-Pine Shaving
}

\author{
Amin Chegenizadeh ${ }^{1}$, Mahdi Keramatikerman ${ }^{2}$, Hamid Nikraz ${ }^{3}$ \\ ${ }^{1}$ Senior Lecturer, Department of Civil Engineering, Curtin University of Technology, Kent Street, Bentley, Perth, \\ Western Australia 6102, Australia. amin.chegenizadeh@curtin.edu.au \\ ${ }^{2}$ Engineer, Arup Australia, 61-73 Sturt Street, Suncorp Tower, Townsville QLD 4810, Australia. \\ mahdi.keramati@arup.com \\ ${ }^{3}$ Professor, Department of Civil Engineering, Curtin University of Technology, Kent Street, Bentley, Perth, \\ Western Australia 6102, Australia. h.nikraz@curtin.edu.au
}

\begin{abstract}
Shear rate is an important parameter in analysis of the shear strength of the soil. Whilst many studies conducted to investigate efficacy of the different materials on peak shear strength of the soil, importance of shear rate has been ignored. This study aims to investigate effect of three different shear rate (i.e., $0.2,0.3,0.4 \mathrm{~mm} / \mathrm{min}$ ) on peak shear strength of the sand mixed with $2 \%$ fiber $(\mathrm{F})$ when mixed with different pine shaving (PS) contents (i.e., 5, 10, 15\%) by performing a series of experimental direct shear testing. The results of analysis showed that increasing the shear rate increased the peak shear strength and may cause less accurate result.
\end{abstract}

Key words: Soil Mechanics; Direct Shear; Experimental Analysis; Shear Strength; Sand; Fiber, Pine Shaving

\section{INTRODUCTION}

Soil and its complex behaviore should be studied due to stress distribution effect on the designs and also the effective parameters on stresses itself.[1,2,3] Application of different additives to improve mechanical behavior of soil is a common approach in soil stabilization. This method not only is a cost-effective method, helps to reduce the carbon footprint in the environment whilst the outcome has not been compromised. Different by-product materials have been investigated in this light. The by-products such as fly ash [4-6], slag [7-10], and fiber [12-18] widely has been considered. Lime as a cementitious agent widely has been used in soil stabilization projects $[19,20]$. Recycled tyre in form of crumbled or powdered has been widely utilized [21-23]. Sawdust [24] is another by-product that widely has been used to investigate shear strength behavior of soil. Improvement of the shear strength of contaminated soil is another venue for implementation of the by-products $[25,26]$. Investigation effect of parameters and by-products on liquefaction resistance of soil has been widely investigated [27-29]. Geo-grid also being applied in soil and different behavior was observed.[30,31]. While the compressive strength of materials important [32], from the reviewed literature, however there has been attempt to consider shear strength by inclusion of by product/fiber [33-42], it can be clearly seen that the shear rate impacts on peak shear strength of soils have been considered to less extent .In particular, pine shaving that has not considered in previous studies when mixed with fiber and sand. Therefore, this study designed to investigate effect of different shear rates on peak shear strength of sand mixed with fiber and pine shaving. This study of researches in Curtin University on soil stabilsation techniques.

\section{MATERIALS}

As indicated, this study investigates shear strength behavior of sand mixed with fiber and shaving pine. Therefore, the main materials used to perform this study includes sand, fiber, and pine shaving. The following sections provide more details regarding used materials.

\subsection{Sand}

The main material used in this study was sand. To perform the tests, Perth sand was employed. This sand had a specific gravity $(G s)$ of 2.65 and uniformity coefficient $(\mathrm{Cu})$ equal to 0.6 .

\subsection{Pine Shaving}

Pine shaving was sourced from a local source in Perth, Western Australia. The average size of PS was $0.5 \mathrm{~mm}$.

\subsection{Fibre}

Propylene fibre (PF) was used in this study with characteristics such as tensile moduli of $0.6 \mathrm{GPa}$ and a elongations at break in the range $92 \%$.

\section{SHEAR TEST PROGRAM}

The direct shear test was utilized to perform the tests. This is common testing device in evaluating shear strength of the soil, and more information can be found in soil mechanics books in this regard. Testing was performed at three different normal stresses of 100,150 , and $200 \mathrm{kPa}$. Also, three shear rates of $0.2,0.3$, and $0.4 \mathrm{~mm} / \mathrm{min}$ were utilized to perform the tests. Also, prior to perform the tests, a series of compaction 
testing performed to investigate the optimum moisture content (OMC) and the maximum dry density (MDD). This information will be utilized at the time of sample mixture and preparation. Table 1 shows the testing programs used to utilize the tests.

Table 1: Testing program utilized in this study

\begin{tabular}{|c|c|c|c|}
\hline Sample ID & PS (\%) & $\begin{array}{c}\text { Shear Rate } \\
(\mathbf{m m} / \mathbf{m i n})\end{array}$ & $\begin{array}{c}\text { Fiber } \\
(\boldsymbol{\%})\end{array}$ \\
\hline S-2F-5PS & 5 & $0.2,0.3,0.4$ & 2 \\
\hline S-2F-10PS & 10 & $0.2,0.3,0.4$ & 2 \\
\hline S-2F-15PS & 15 & $0.2,0.3,0.4$ & 2 \\
\hline
\end{tabular}

\section{TEST RESULTS}

\subsection{Compaction Results}

Table 2 shows the compaction characteristics of the used mixtures. As seen, addition of PS increased the OMC and reduced MDD value of the mixtures. In fact, when pine shaving mixed with the soil, the mixture would need more moisture to have a similar performance and workability with mixtures with no pine shaving. Therefore, an increase in $\mathrm{OMC}$ and a reduction in MDD has been recorded.

Table 2: Results of compaction tests

\begin{tabular}{|c|c|c|c|}
\hline Sample ID & PS (\%) & OMC (\%) & MDD \\
\hline S-2F-5PS & 5 & 12 & 1.61 \\
\hline S-2F-10PS & 10 & 14 & 1.58 \\
\hline S-2F-15PS & 15 & 15.2 & 1.51 \\
\hline
\end{tabular}

\subsection{Direct Shear Tests}

Figure 1 to 3 shows the results of shear strength for specimens with 5,10 , and $15 \%$ pine shaving when the test run at $0.2 \mathrm{~mm} / \mathrm{min}$. As can be seen, addition of PS increased the peak shear strength at all three tested normal stresses. Similarly, an increasing trend can be seen when the tests were run at a shearing rate of $0.3 \mathrm{~mm} / \mathrm{min}$. This fact can be seen in Figure 4 to 6. Likewise, the specimens showed a similar behavior at $0.4 \mathrm{~mm} / \mathrm{min}$ when 5,10 , and $15 \%$ PS were added into the specimens. Figure 7 to 9 shows this behavior. This behaviour can be attributed to the formed bonds amongst sand, fiber and the pine shaving that increasing the pine shaving increases these bonds amongst soil particles.

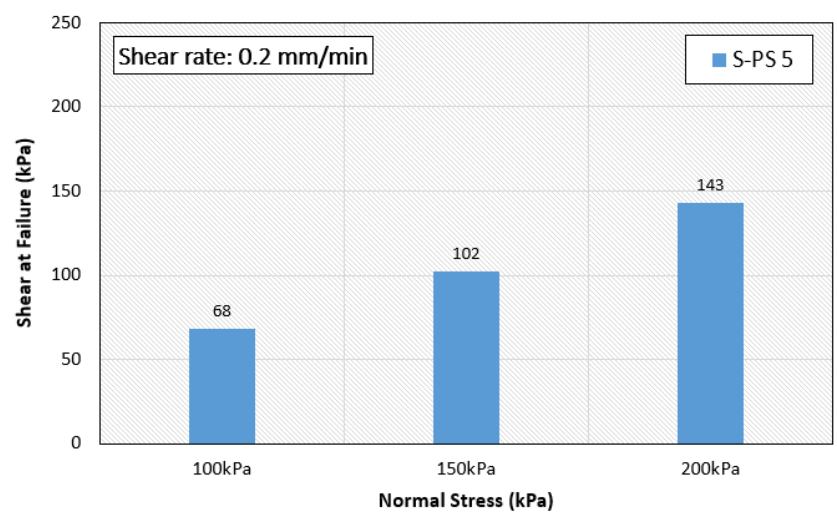

Figure 1: Shear at failure at $0.2 \mathrm{~mm} / \mathrm{min}, 5 \% \mathrm{PS}, 2 \% \mathrm{~F}$.

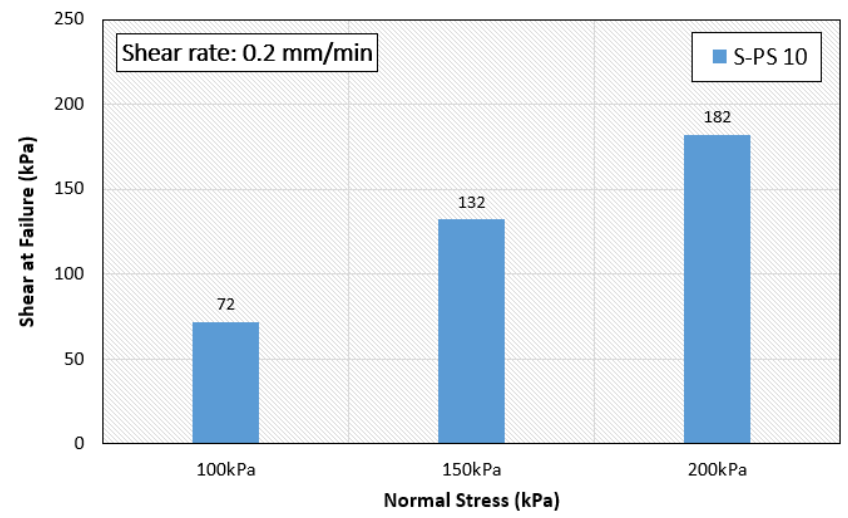

Figure 2: Shear at failure at $0.2 \mathrm{~mm} / \mathrm{min}, 10 \% \mathrm{PS}, 2 \% \mathrm{~F}$.

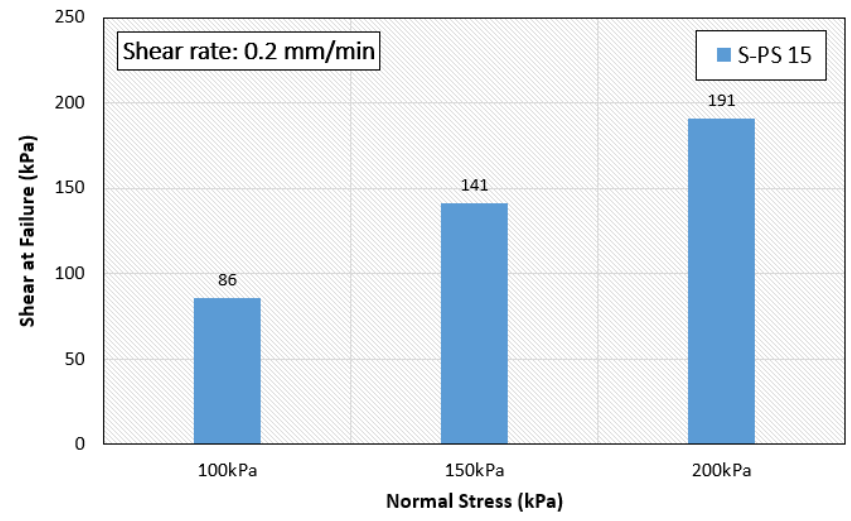

Figure 3: Shear at failure at $0.2 \mathrm{~mm} / \mathrm{min}, 15 \% \mathrm{PS}, 2 \% \mathrm{~F}$.

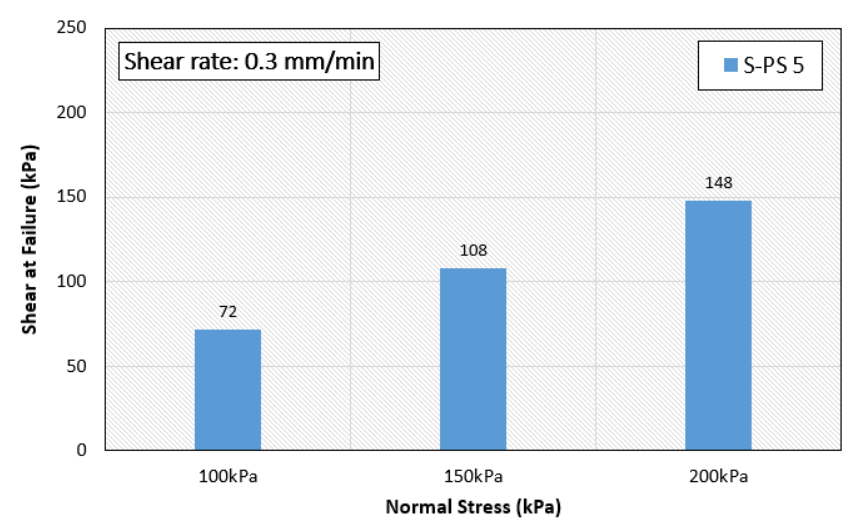

Figure 4: Shear at failure at $0.3 \mathrm{~mm} / \mathrm{min}, 5 \% \mathrm{PS}, 2 \% \mathrm{~F}$. 


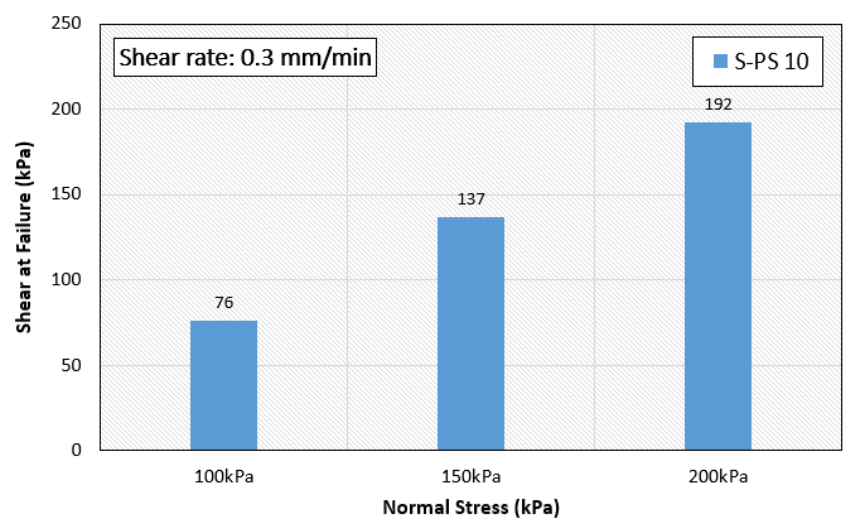

Figure 5: Shear at failure at $0.3 \mathrm{~mm} / \mathrm{min}, 10 \% \mathrm{PS}, 2 \% \mathrm{~F}$.

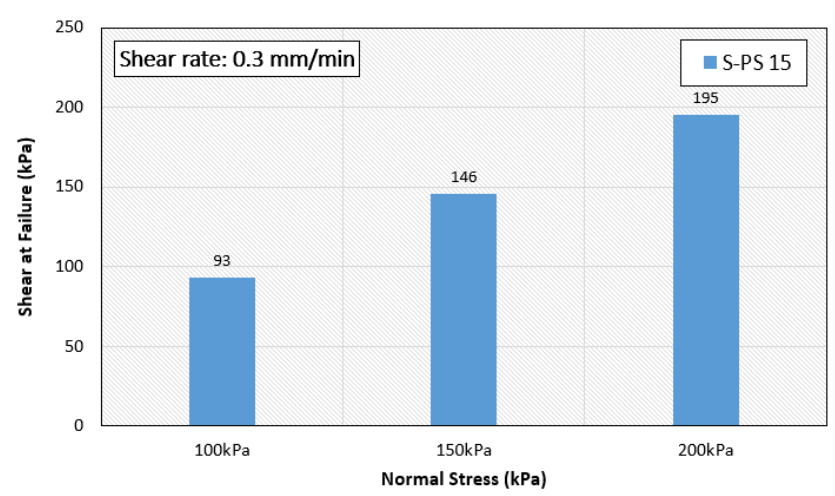

Figure 6: Shear at failure at $0.3 \mathrm{~mm} / \mathrm{min}, 15 \% \mathrm{PS}, 2 \% \mathrm{~F}$.

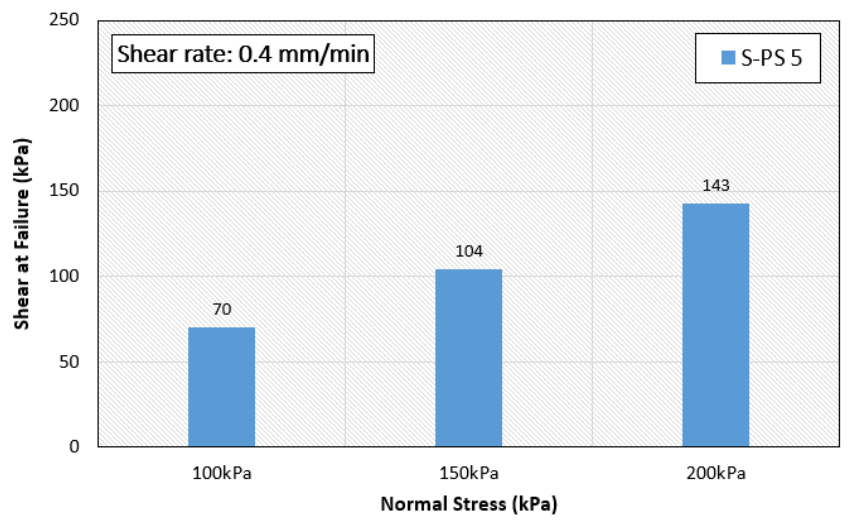

Figure 7: Shear at failure at $0.4 \mathrm{~mm} / \mathrm{min}, 5 \% \mathrm{PS}, 2 \% \mathrm{~F}$.

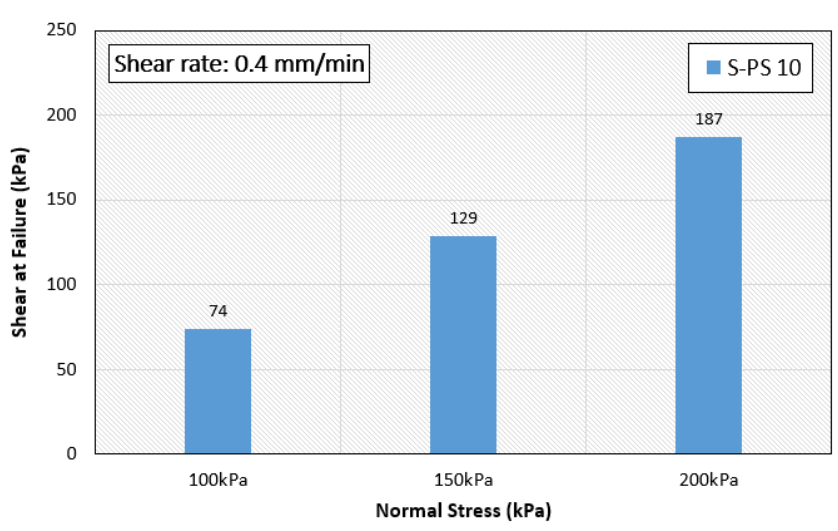

Figure 8: Shear at failure at $0.4 \mathrm{~mm} / \mathrm{min}, 10 \% \mathrm{PS}, 2 \% \mathrm{~F}$.

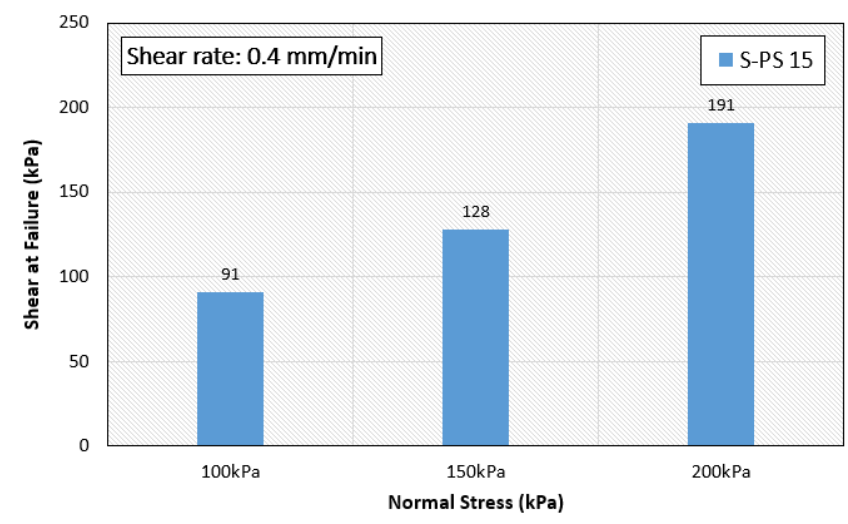

Figure 9: Shear at failure at $0.4 \mathrm{~mm} / \mathrm{min}, 15 \% \mathrm{PS}, 2 \% \mathrm{~F}$.

\section{CONCLUSION}

Shear rate is an important parameter that has been considered to less extent to dat. This study investigated effect of three shearing rates of $0.2,0.3,0.4 \mathrm{~mm} / \mathrm{min}$ by performing a series of direct shear tests on mixtures of sand, fiber, and pine shaving. At the first stage, compaction testing was conducted on the mixtures and the optimum moisture content (OMC) and maximum dry density (MDD) values were calculated. In the next stage, the direct shear testing was conducted. Three pine shaving were considered (i.e., 5, 10, 15\%). The results showed that increasing the pine shaving increased the shear strength under all three tested normal stresses of 100, 150, and $200 \mathrm{kPa}$. However, the results showed that increasing the shearing rate increased the shear strength which might be led to inaccurate results.

\section{REFERENCES}

[1] Al-rkaby, A.H.J., Chegenizadeh, A., Nikraz, H.R. Directional-dependence in the mechanical characteristics of sand: a review , International Journal of Geotechnical Engineering 2016 10(5), pp. 499-509 https://doi.org/10.1080/19386362.2016.1173965

[2] Ngo DH, Horpibulsuk S, Suddeepong A, Hoy M, Chinkulkijniwat A, Arulrajah A, et al. Compressibility of ultra-soft soil in the Mae Moh Mine, Thailand. Engineering Geology. 2020;271:105594. https://doi.org/10.1016/j.enggeo.2020.105594

[3] Chegenizadeh, A., Ghadimi, B., Nikraz, H., Şimşek, M. A novel two-dimensional approach to modelling functionally graded beams resting on a soil medium ,

Structural Engineering and Mechanics 2014 51(5), pp. 727-741

[4] Keramatikerman $M$, Chegenizadeh A, Nikraz $H$. Experimental study on effect of fly ash on liquefaction resistance of sand Soil Dynamics and Earthquake Engineering,2017. 93, 1-6

[5] Arulrajah A, Kua T-A, Horpibulsuk S, Phetchuay C, Suksiripattanapong C, Du Y-J. Strength and 
microstructure evaluation of recycled glass-fly ash geopolymer as low-carbon masonry units. Construction and Building Materials. 2016;114:400-6.

[6] Arulrajah A, Yaghoubi M, Disfani MM, Horpibulsuk S, Bo MW, Leong M. Evaluation of fly ash- and slag-based geopolymers for the improvement of a soft marine clay by deep soil mixing. Soils and Foundations. 2018;58(6):1358-70.

https://doi.org/10.1016/j.sandf.2018.07.005

[7] Hasan, U., Chegenizadeh, A., Budihardjo, M.A., Nikraz, H. Experimental Evaluation of Construction Waste and Ground Granulated Blast Furnace Slag as Alternative Soil Stabilisers Geotechnical and Geological Engineering 2016 34(6), pp. 1707-1722

[8] Sabbar AS, Chegenizadeh A, Nikraz H. Static liquefaction of very loose sand-slag-bentonite mixtures. Soils and Foundations. 2017 Jun 1;57(3):341-56.

[9] Amini O, Ghasemi M. Laboratory study of the effects of using magnesium slag on the geotechnical properties of cement stabilized soil. Construction and Building Materials. 2019;223:409-20.

[10] Guda S. Efficacy of cement-stabilized GBS and GGBS cushions in improving the performance of expansive soils. Jordan Journal of Civil Engineering. 2016;10(4).

[12] Chegenizadeh A, Nikraz H. Permeability test on reinforced clayey sand. World Academy of Science, Engineering and Technology. 2011;54:130-3.

[13] Kar RK, Pradhan PK, Naik A. Effect of randomly distributed coir fibers on strength characteristics of cohesive soil. The Electronic Journal of Geotechnical Engineering. 2014;19:1567-83.

[16] Chegenizadeh, A., Nikraz, H. Composite soil: Fiber inclusion and strength Advanced Materials Research 2011, 308-310, pp. 1646-1650

[17] Chegenizadeh, A., Nikraz, H. Investigation on compaction characteristics of reinforced soil Advanced Materials Research 2011 261-263, pp. 964-968

[18] Chegenizadeh, A., Nikraz, H. Investigation on strength of fiber reinforced clay Advanced Materials Research 2011 261-263, pp. 957-963

[19] Gidday BG, Mittal S. Improving the characteristics of dispersive subgrade soils using lime. Heliyon. 2020;6(2):e03384. https://doi.org/10.1016/j.heliyon.2020.e03384

[20] Locat J, Bérubé MA, Choquette M. Laboratory investigations on the lime stabilization of sensitive clays: shear strength development. Canadian Geotechnical Journal. 1990 Jun 1;27(3):294-304.

[21] Chegenizadeh A, Keramatikerman M, Panizza S, Nikraz $\mathrm{H}$. Effect of powdered recycled tire on sulfate resistance of cemented clay. Journal of Materials in Civil Engineering. 2017 Oct 1;29(10):04017160.

[22] Chegenizadeh, A., Keramatikerman, M., Dalla Santa, G., Nikraz, H. Influence of recycled tyre amendment on the mechanical behaviour of soil-bentonite cut-off walls Journal of Cleaner Production 2018 177, pp. 507-515

[23] Rao GV, Dutta RK. Compressibility and strength behaviour of sand-tyre chip mixtures. Geotechnical \& Geological Engineering. 2006 Jun 1;24(3):711-24.

[24] Keramatikerman, M., Chegenizadeh, A., Nikraz, H. An investigation into effect of sawdust treatment on permeability and compressibility of soil-bentonite slurry cut-off wall Journal of Cleaner Production 2017, 162, pp. 1-6

https://doi.org/10.1016/j.jclepro.2017.05.160

[25] Inkham R, Kijjanapanich V, Huttagosol P, Kijjanapanich P. Low-cost alkaline substances for the chemical stabilization of cadmium-contaminated soils. Journal of Environmental Management. 2019;250:109395.

[26] Zou Q, Li Da, Jiang J, Aihemaiti A, Gao Y, Liu N, et al. Geochemical simulation of the stabilization process of vanadium-contaminated soil remediated with calcium oxide and ferrous sulfate. Ecotoxicology and Environmental Safety. 2019;174:498-505.

[27] Keramatikerman M, Chegenizadeh A. Effect of particle shape on monotonic liquefaction: Natural and crushed sand. Experimental Mechanics. 2017 Oct 1;57(8):1341-8.

[28] Liyanapathirana DS, Poulos HG. A numerical model for dynamic soil liquefaction analysis. Soil Dynamics and Earthquake Engineering. 2002 Oct 1;22(9-12):1007-15.

https://doi.org/10.1016/S0267-7261(02)00125-2

[29] Takahashi A, Takemura J. Liquefaction-induced large displacement of pile-supported wharf. Soil Dynamics and Earthquake Engineering. 2005 Dec 1;25(11):811-25.

[30]Al-Rkaby, A.H.J., Chegenizadeh, A., Nikraz, H.R. Anisotropic strength of large scale geogrid-reinforced sand: Experimental study Soils and Foundation 2017 57(4), pp. 557-574

[31]Al-rkaby, A.H.J., Chegenizadeh, A., Nikraz, H.R. Cyclic behavior of reinforced sand under principal stress rotation Journal of Rock Mechanics and Geotechnical Engineering 2017 9(4), pp. 585-598

[32] Mohd Fakri Muda, Saffuan Wan Ahmad, Fadhluhartini Muftah, Mohd Syahrul Hisyam Mohd Sani, Mechanical Behaviour of Mortar Made with Washed Bottom Ash as Sand Replacement, International Journal of Emerging Trends in Engineering Research, 20197 (9).

[33] Chegenizadeh, A., Nikraz, H. Shear test on reinforced clay Advanced Materials Research 2011, 250-253, pp. 3223-3227

[34] Shalabi FI, Asi IM, Qasrawi HY. Effect of by-product steel slag on the engineering properties of clay soils. Journal of King Saud University - Engineering Sciences. 2017;29(4):394-9. 
[35] Schjønning P, Lamandé M, Keller T, Labouriau R. Subsoil shear strength - Measurements and prediction models based on readily available soil properties. Soil and Tillage Research. 2020;200:104638.

https://doi.org/10.1016/j.still.2020.104638

[36] Tsuchida T, Kitade K, Tanaka M, Kang G-o, Kaya K. Evaluation of design shear strength of intermediate soil for construction of breakwater at Port of Sakai. Soils and Foundations. 2020.

[37] Amiri E, Emami H, Mosaddeghi MR, Astaraei AR. Shear strength of an unsaturated loam soil as affected by vetiver and polyacrylamide. Soil and Tillage Research. 2019;194:104331.

[38] Zhang C, Wang X, Zou X, Tian J, Liu B, Li J, et al. Estimation of surface shear strength of undisturbed soils in the eastern part of northern China's wind erosion area. Soil and Tillage Research. 2018;178:1-10.

[39] Müller-Vonmoos M, Løken T. The shearing behaviour of clays. Applied clay science. 1989 Jun 1;4(2):125-41. https://doi.org/10.1016/0169-1317(89)90004-5

[40] He P, Mu Y, Yang Z, Ma W, Dong J, Huang Y. Freeze-thaw cycling impact on the shear behavior of frozen soil-concrete interface. Cold Regions Science and Technology. 2020;173:103024.

https://doi.org/10.1016/j.coldregions.2020.103024

[41]Yaghoubi M, Arulrajah A, Disfani MM, Horpibulsuk S, Bo MW, Darmawan S. Effects of industrial by-product based geopolymers on the strength development of a soft soil. Soils and Foundations. 2018;58(3):716-28.

https://doi.org/10.1016/j.sandf.2018.03.005

[42] Dahale PP, Nagarnaik PB, Gajbhiye AY. Engineering Behavior of Remolded Expansive Soil with Lime and Flyash. Materials Today: Proceedings. 2017;4(9):10581-5. https://doi.org/10.1016/j.matpr.2017.06.423 